\title{
A new mutant transthyretin (Arg 10) associated with familial amyloid polyneuropathy
}

\author{
T Uemichi, J R Murrell, S Zeldenrust, M D Benson
}

\begin{abstract}
We report a new kindred with systemic amyloidosis presenting as peripheral neuropathy in the sixth and seventh decades of life. Polymorphism in exon 2 of the transthyretin (TTR) gene was suggested by single strand conformation polymorphism analysis and determined by direct DNA sequencing. We also developed restriction fragment length polymorphism analysis by polymerase chain reaction using a primer with an induced mutation. The point mutation (cytosine for thymine at position 1038 of the TTR gene) is responsible for substitution of arginine for cysteine at position 10 of the TTR molecule. It is hypothesised that the TTR molecules which have no cysteine have a unique structure in heterozygous TTR polymers and are responsible for amyloid fibril formation.

( $\exists$ Med Genet 1992;29:888-91)
\end{abstract}

Familial amyloid polyneuropathy (FAP) is a late onset autosomal dominant disorder characterised by amyloid deposition in various organs including peripheral nerves. Recently, single amino acid changes in the amyloid precursor protein, transthyretin (TTR) in most cases, have been shown to relate to the disease, but the mechanism of the onset is not known. ${ }^{1}$

We examined TTR genes of patients with FAP by single strand conformation polymorphism (SSCP) analysis and direct DNA sequencing and found a mutant TTR gene, which codes for arginine at position 10 in place of cysteine. In addition, we developed a restriction fragment length polymorphism (RFLP) analysis to detect the mutant gene.

\section{Case reports}

CASE 1 (IV·13, FIG 1)

At the age of 59, the proband developed loss of appetite and dysgeusia leading to a $22 \mathrm{~kg}$ weight loss, and painful paraesthesiae in the fingertips followed by tingling and loss of sensation. He had urinary frequency, incomplete bladder emptying, and impotence. While he at first had increased flatus, two years later he developed diarrhoea and subsequently had constipation. When first evaluated sensory deficits had ascended to the upper arms and upper thighs. By the age of 62 years he noted muscle cramping and distal weakness. On examination, there was diffuse distal weakness, moderate for hand intrinsic muscles and mild for arm and forearm muscles, as well as anterolateral leg muscles. Pinprick and light touch were severely reduced to the level of the hips and shoulders. Vibration sense was mildly reduced in hands and absent in toes. All deep tendon reflexes were absent. He could walk on his toes, poorly on his heels, but could hop. The following laboratory investigation were normal or negative: urine analysis, haematological study, erythrocyte sedimentation rate, rheumatoid factor, antinuclear antibody, serum and urine protein electrophoresis and immunoelectrophoresis, and hepatorenal functions. The electrocardiogram showed a normal sinus rhythm and a probable inferior infarct. The echocardiogram showed normal left ventricular cavity size and ejection fraction, but increased left ventricular wall thickness and mild mitral regurgitation by Doppler. Nerve conduction studies showed absent sensory nerve action potentials in median, ulnar, and sural nerves and low amplitude compound muscle action potential in median, ulnar, peroneal, and posterior tibial nerves. A subcutaneous fat aspirate stained with Congo red was positive for amyloid. Sural nerve biopsy

\footnotetext{
Departments of

Medicine and Medical and Molecular

Genetics, and The

Richard L Roudebush

Veterans

Administration

Medical Center,

Indiana University

Medical Center,

Indianapolis, Indiana

46202, USA.

$T$ Uemichi

J R Murrell

$S$ Zeldenrust

M D Benson

Correspondence to Dr Benson.

Received 23 March 1992. Revised version accepted 18 May 1992.
}

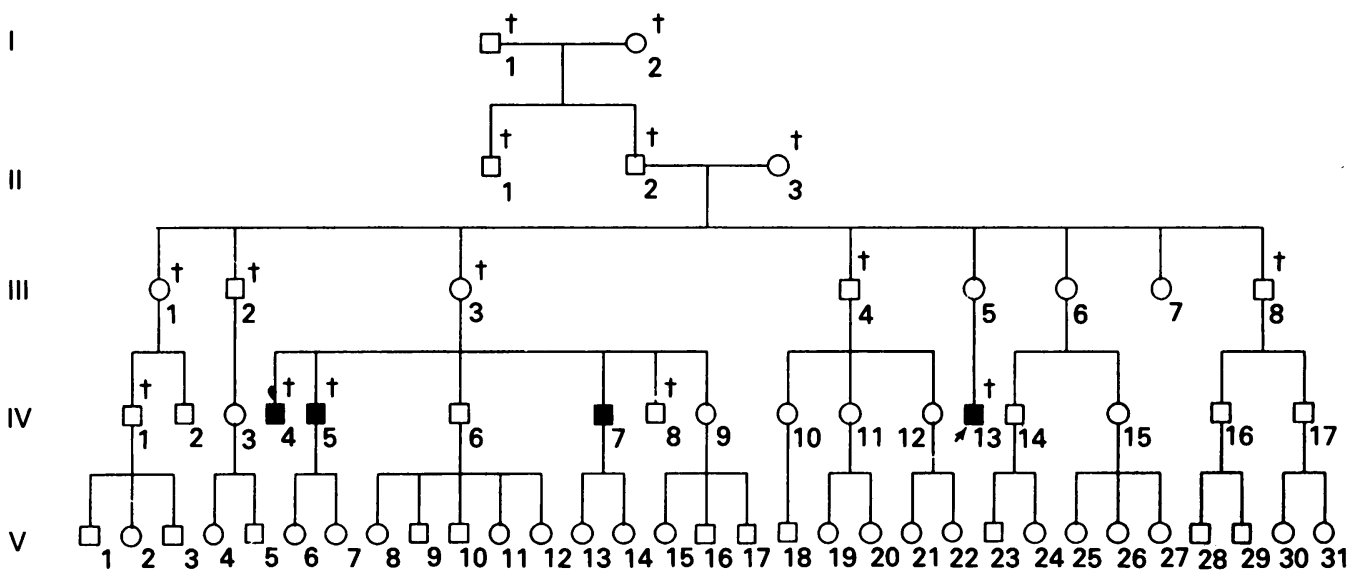

Figure 1 Family pedigree. Solid symbols indicate affected subjects. Arrow denotes proband. 
showed severe reduction of the density of myelinated fibres in a diffuse fashion. Methyl violet stains showed unequivocal metachromasia around small endoneurial microvessels.

One year later, he had vitreous opacities in his eyes. He became emaciated and died at the age of 64 .

The family pedigree is shown in fig 1 . The family is of Hungarian descent with all members at present living in the eastern United States. The proband's mother (III-5), who is 87 years old, has no symptoms of neuropathy. His maternal grandfather (II-2) died at 72 of heart disease and his grandmother (II.3) died at 69 of cancer of the liver. Three of his cousins, whose mother (III.3) died at 68 of heart disease, had similar symptoms.

CASE 2 (IV·4)

The oldest cousin noticed numbness in all four extremities at the age of 68 , which progressed slowly and involved the arms below the elbows and the legs below the knees.

The general medical examination was remarkable for râles over the lower lobes of the lungs and a systolic murmur at the left lower sternal border. His lower extremities were markedly atrophic. There was muscle weakness, mild in the proximal upper extremities and moderate in the distal upper extremities and throughout the lower extremities. Sensation to pinprick, temperature, light touch, vibration, and proprioception was decreased in the lower extremities to mid-thigh and in the upper extremities to the elbows. Reflexes were decreased in the upper extremities and diminished in the lower extremities. Gait was wide based and unsteady and he was unable to walk on his heels or toes and unable to tandem walk.

A number of serum studies showed only a polyclonal increase in immunogloblins on serum protein electrophoresis. Rectal and nerve biopsies were read as negative for amyloid deposition. However, reanalysis of these tissues with Congo red staining after the patient's death showed unequivocal deposits of amyloid.

He developed congestive heart failure and died at the age of 70 .

CASE 3 (IV.5)

The second oldest cousin had a $27 \mathrm{~kg}$ weight loss and severe painful paraesthesiae in his lower extremities. He had a colectomy because of paralytic ileus. He died at the age of 67 with congestive heart failure.

CASE 4 (IV.7)

A younger brother of cases 2 and 3, who is 63 years old, has complained of hypaesthesiae to temperature in his feet since last year.

\section{Materials and methods}

DNA ISOLATION

Total genomic DNA was isolated from peripheral blood cells of cases 1 and 4 and 10 other family members of this FAP kindred and from a biopsied rectal specimen of case $2 .^{2}$

\section{SSCP ANALYSIS}

SSCP was performed according to the method of Orita et al. ${ }^{34}$ DNA fragments containing exons 2,3 , and 4 of the TTR gene $(215 \mathrm{bp}$, $258 \mathrm{bp}$, and $190 \mathrm{bp}$, respectively) were amplified from the proband and normal control DNA by PCR with the primers described previously using GeneAmp PCR reagents (Perkin-Elmer Cetus, Norwalk, CT), $60 \mu \mathrm{mol} / 1$ dNTPs, and $30 \mathrm{nmol} / 1{ }^{32} \mathrm{P}$ labelled dCTP (final concentration). ${ }^{5}$ PCR conditions were: 35 cycles of denaturing at $94^{\circ} \mathrm{C}$ for one minute, annealing at $65^{\circ} \mathrm{C}$ for one minute, and extension at $72^{\circ} \mathrm{C}$ for one minute. PCR products were diluted with 100 volumes of the buffer containing $50 \%$ formamide, $0.05 \%$ SDS, $0.02 \%$ xylene cyanol FF, $0.02 \%$ bromophenol blue, and $10 \mathrm{mmol} / 1 \mathrm{EDTA}$, heated at $95^{\circ} \mathrm{C}$ for five minutes, and loaded onto a $5 \%$ acrylamide gel $(2 \% \mathrm{C}, 40 \mathrm{~cm} \times 20 \mathrm{~cm} \times 0.04 \mathrm{~cm})$. The gel was electrophoresed at $4^{\circ} \mathrm{C}$ for five hours at $40 \mathrm{~W}$, dried, and exposed to Kodak X-Omat film.

\section{DIRECT DNA SEQUENCING}

Direct sequencing of exons 2, 3, and 4 of the TTR gene of cases 1,3 , and 4 was performed as described previously. ${ }^{5}$

\section{RFLP ANALYSIS}

PCR amplified DNA fragments containing exon 2 of the TTR gene of the proband and a normal control were digested with restriction enzyme HgaI (New England Biolabs, Inc, Beverly, MA) at $37^{\circ} \mathrm{C}$ overnight, electrophoresed through $4 \%$ Nusieve GTG agarose gel, stained with ethidium bromide, and photographed under UV light.

DNA samples from 13 members of this kindred (three affected and 10 persons at risk) were examined by PCR induced mutation restriction analysis (PCR-IMRA). A new primer with a mutation arranged to give a recognition site of $B s t \mathrm{UI}$ in the mutant gene (5'-AGGGCACCGGTGAATCCACG-3') was synthesised. PCR was performed with this new primer and E2LP2 primer (5'-AGATCTGCAGAAGTCCTGTGGGAGGGTTCT-3') under the same conditions as described above. ${ }^{5}$ The PCR products were digested with $B s t \mathrm{UI}$ (New England Biolabs, Inc, Beverly, MA) at $60^{\circ} \mathrm{C}$ for an hour and electrophoresed.

\section{Results}

SSCP analysis showed an abnormally migrating band in exon 2 of the proband (fig 2). Direct sequencing of the exon 2 PCR products of cases 1,3 , and 4 showed both thymine and cytosine at position 1038 of TTR (fig 3). ${ }^{6}$ Thus they were heterozygous with both a normal TGT (cysteine) and a variant CGT (arginine) codon at amino acid position 10 of mature TTR. The sequence data on exons 1,3 , and 4 


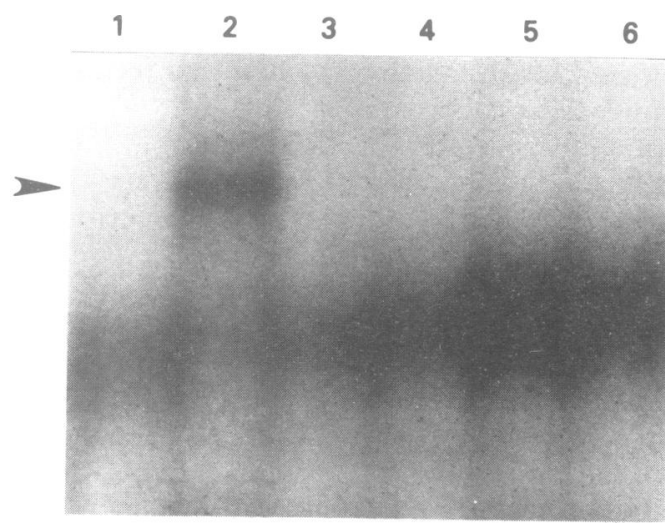

Figure 2 Autoradiograph of SSCP gel for TTR exon 2. Lane 2, proband; lanes 1, 3, 4, 5, and 6, controls. Abnormal migrating band in lane 2 is indicated by an arrow.

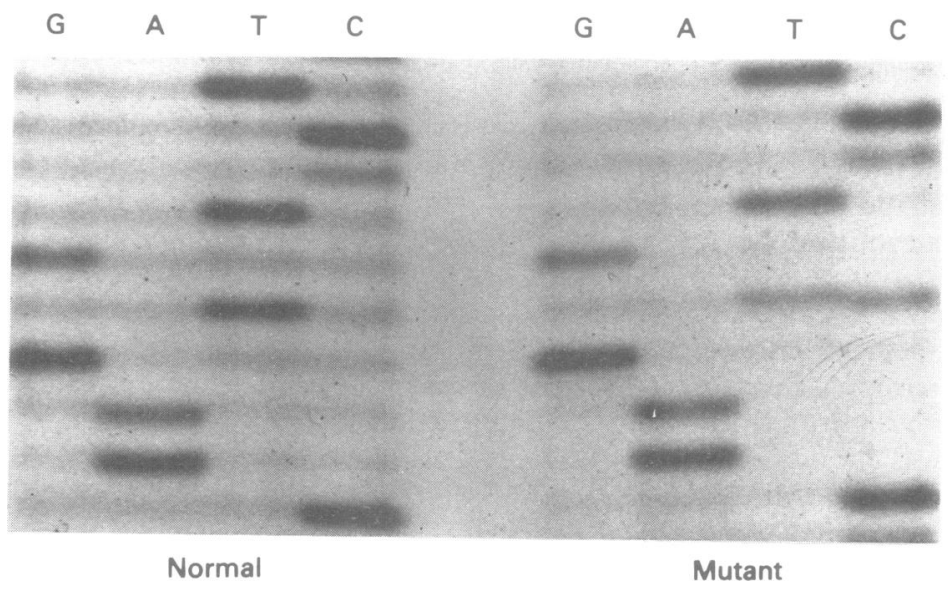

Figure 3 Autoradiograph of direct DNA sequencing of TTR exon 2. Both thymine and cytosine are present at position 1038 of the TTR gene of the proband (indicated by arrow).

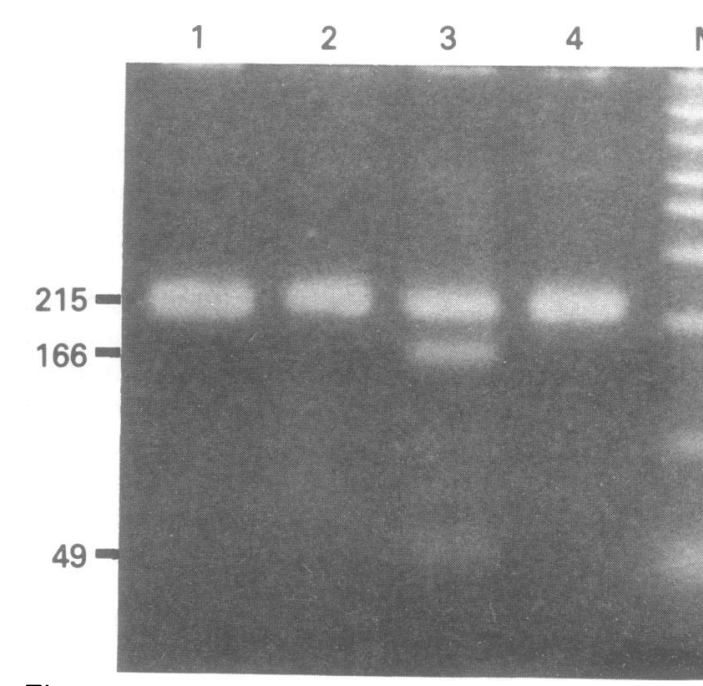

Figure 4 RFLP analysis of Hgal digest of the PCR amplified TTR exon 2. Lane 1, HgaI digested PCR product of control; lane 2, undigested PCR product of control; lane 3, HgaI digested PCR product of the proband; lane 4, undigested PCR product of the proband. Lane M, DNA size marker (BioMarker LOW, Bio Ventures, Inc). The figures on the left denote the sizes of the bands in base pairs.

digestion. The use of restriction enzyme analysis for detection of DNA mutation requires complete and reproducible DNA digestion to prevent false negative results caused by poor digestion. In this respect, PCR-IMRA with $B s t \mathrm{UI}$ is superior to $\mathrm{HgaI}$ digestion for detection of the Arg10 mutation. Bst UI digestion is less affected by conditions and, in addition, this enzyme is about 100 times less expensive than $\mathrm{HgaI}$.

We examined the DNA of 13 subjects in this pedigree and found seven who carry this mutant gene. It is noticeable that none of three female mutant gene carriers, who are 87,85 , and 76 years old, have symptoms of the disease, while four of five male carriers, including one patient whose DNA was not available for testing, developed the disease in their 50s or $60 \mathrm{~s}$. It has been observed in other types of FAP that males are affected predominantly or affected at younger ages than females. ${ }^{7-10}$ This might suggest that one factor which enhances amyloid deposition relates to male sex.

Affected subjects in this kindred showed sensory and motor neuropathy, bowel disorder, sexual impotence, cardiomyopathy, and vitreous opacity, but no kidney dysfunction. Clinical features of the neuropathy are similar to those of type I FAP, except for age of onset which is later than the mean age of onset of type I. ${ }^{11}{ }^{12}$ Study on a larger number of subjects over a longer period is necessary before reaching definite conclusions on the clinical features of FAP associated with this molecular abnormality.

About 30 different amino acid substitutions of TTR have been reported to cause amyloidosis. The mechanisms whereby variant TTR proteins are involved in deposition in tissues as amyloid fibrils have not been determined. Normal TTR monomer has one free cysteine at position 10. It has been suggested from in vitro experiments that disulphide bond formation between TTR molecules might play some 


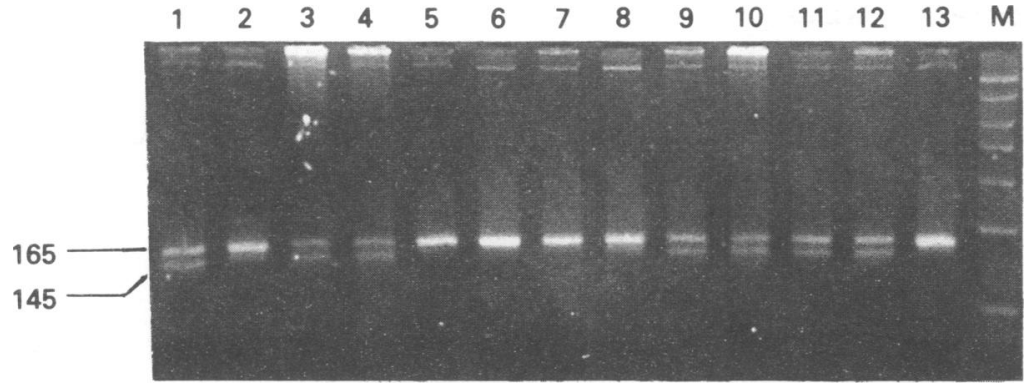

Figure 5 PCR-IMRA of BstUI digest of the TTR exon 2. Lane 1, IV.4; lane 4, IV 7 ; lane 10,IV 10 ; lanes $2,3,5,6,7,8,9,11,12$, and 13, subjects at risk in this kindred. Lane $M, D N A$ size marker.
DNA on the integrity of DNA. Am $f$ Med Genet 1987;27:379-90.

3 Orita M, Suzuki Y, Sekiya T, Hayashi K. Rapid and sensitive detection of point mutations and DNA polymorphisms using the polymerase chain reaction. Genomics phisms using

4 Orita M, Iwahana H, Kanazawa H, Hayashi K, Sekiya T. Detection of polymorphisms of human DNA by gel electrophoresis as single-strand conformation polymorphisms. Proc Natl Acad Sci USA 1989;86:2766-70.

5 Nichols WC, Liepnieks JJ, McKusick VA, Benson MD. Direct sequencing of the gene for Maryland/German familial amyloidotic polyneuropathy type II and genotyping by allele-specific enzymatic amplification. Genomics 1989;5:535-40.

6 Tsuzuki T, Mita S, Maeda S, Araki S, Shimada K. Structure of human prealbumin gene. $f$ Biol Chem 1985;260:12224-7.

7 Sequeiros J, Sousa A, Coelho T. Sex differences and agedependent penetrance FAP-type I. In: Natvig JB, Forre dependent penetrance FAP-type I. In: Natvig JB, Forre Proceedings of the sixth international symposium on amyloiProceedings of the sixth international symposium on amyloi-
dosis. Dordrecht: Kluwer Academic Publishers, dosis. Dord

8 Ikegawa S, Hanyu N, Hongo $M$, et al. Hereditary generalized amyloidosis with polyneuropathy: clinicopathological study of 65 Japanese patients. Brain 1987;110:315-37.

role in amyloid fibril formation. ${ }^{1314}$ It is hypothesised that the conformational modification of TTR protein induced by an amino acid substitution results in the resistance to proteolytic digestion and solubilisation. This variant TTR, which has no cysteine, may cause structural changes in the heterozygous TTR dimer and tetramer that lead to polymerisation of TTR molecules.

This work was supported by Veterans Affairs Medical Research (MRIS 583-0888), and grants from RR-00750 (GCRC), United States Public Health Service, NIDDK-34881, NIDDK-42111, National Institute of Arthritis Metabolism and Digestive Diseases (AM20582), the Arthritis Foundation, the Grace M Showalter Foundation, and the Marion $\mathrm{E}$ Jacobson Fund.

1 Benson MD. Inherited amyloidosis. $f$ Med Genet Madisen L, Hoar DI, Holroyd CD, Crisp M, Hodes ME. DNA banking: the effects of storage of blood and isolated tion in apolipoprotein AI in the Iowa type of familial amyloidotic polyneuropathy. Genomics 1990;8:318-23.

10 Uemichi $\mathrm{T}$, Ueno S, Fujimura $\mathrm{H}$, et al. Familial amyloid polyneuropathy related to transthyretin Gly42 in a Japanese family. Muscle Nerve 1992;15:904-11.

11 Coutinho P, Silva M, Lima JL, Barbosa AR. Forty years of experience with type I amyloid neuropathy: review of 483 , eds. Amyloid and amyloidosis 1979. Proceedings of the third international symposium on amyloidosis. Amsterdam: Excerpta Medica, 1980:88-98.

Ikegawa S, Yui S, Araki S, Ando Y, Miyazaki A. Reevaluation of 134 patients with familial amyloidotic polyneuropathy (FAP) in Japan, Kumamoto focus. In: Natvig JB, Forre $\emptyset$, Husby G, et al, eds. Amyloid and amyloidosis 1990. Proceedings of the sixth international symposium on amyloidosis. Dordrecht: Kluwer Academic Publishers, 1991:675-8.

13 Hamilton JA, Steinrauf LK, Liepnieks J, Benson MD. Xray crystal structure of the Met-30 variant of human prealbumin (transthyretin). In: Natvig JB, Forre $\emptyset$, Husby G, et al, eds. Amyloid and amyloidosis 1990 . Proceedings of the sixth international symposium on amyloidosis. Dordrecht: Kluwer Academic Publishers, 1991:579-82.

14 Migita S, Takegami M, Benson MD. Disulfide bond formation of transthyretin (TTR) as possible initial step of familial amyloid polyneuropathy (FAP). In: Natvig JB, Forre Ø, Husby G, et al, eds. Amyloid and amyloidosis 1990. Proceedings of the sixth international symposium on amyloidosis. Dordrecht: Kluwer Academic Publishers,
1991:583-6.
9 Nichols WC, Gregg RE, Brewer B, Benson MD. A mutaexperine 